\title{
My Teacher, My Master and My Friend for Life: Or the Person, the Scholar Who Determined My Fate
}

\section{Galina Glukhova}

Federal State Educational Higher Education Institution Udmurt State University, Izhevsk

Although I have had in my life many interesting meetings and acquaintances, awareness grows with the years that the characters of those who particularly influenced me, who raised me, who helped me are engraved in my memory. Undoubtedly, my parents. Moreover, in the life of each of us, there have been teachers thanks to whom our life path has found its direction. Tatiana Grigoryevna Vladykina has played in my life such a function; she is a gifted scholar, a formidable teacher, a wise mentor, a real friend for life. Meeting her has determined my adult fate.

It was in 1993, in spring. I was an assistant at the chair of Udmurt literature and literature of the people of Russia at the Udmurt State University. After a regular lecture about Udmurt folklore, I went to the chair. As I remember now, the seminar issue was "small genres in folklore". Every time I taught this subject, 


\section{Galina Glukhova}

something in my head did not fit: why does the genre of paroemia belong to the "small genres"? Proverbs contain such depths of folk wisdom! I was as always troubled and this time I asked Tatiana Vladykina who, by a happy chance, happened to be at the chair. She answered my question: "If you want an answer to your question, come and do a $\mathrm{PhD}$ with me". And immediately she named the topic for my future $\mathrm{PhD}$ : "The poetics of the Udmurt lyrical songs". I was extremely surprised by this unexpected proposal.

This event determined my fate. In 1994, I became a doctoral student at the department of folklore and literature at the Udmurt Institute for History, Language and Literature at the Ural branch of the Russian Academy of Sciences; my supervisor was T. G. Vladykina, $\mathrm{PhD}$ in philological sciences, senior researcher and someone with a peculiar intuition.

She followed her students with a keen attention and, depending on their interests, proposed topics for their dissertations. When she identified in them a trend towards abstract thinking, she proposed a corresponding subject for scientific research. She was also convinced that the final choice should be the responsibility of the student, who must like the problematics, must be attracted by it. Her task was merely to adjust this choice, to orient it. Her scientific as well as human sensitivity, this is her characteristic, the style of her multifaceted nature. Therefore, when I entered doctoral studies, I was proposed another topic, "the symbolic of mummery in Udmurt's traditional culture", and I worked on it with immense pleasure (photo 1).

Tatiana Vladykina taught her doctoral students the culture of scientific creation, scientific ethics. She injected us, her doctoral students, with love of research, gave us the opportunity to taste science, get the feel of a scientific school; she helped us write scientific articles, taught us this art. I remember how genuinely she rejoiced at our first hard-won scientific articles in some collection. 
We attended with constant interest the methodologic seminars led by Tatiana Vladykina. She prepared all of our meetings thoroughly and responsibly. I always marvelled and marvel yet at her love of folklore. She always talks about complicated topics with passion and inspiration, making them understandable and accessible. Such is my teacher and mentor, concentrated, responsible, dedicated to her task.

Investigating oral creations, she taught us its poetics, the genres, and did not limit herself to text analysis. She paid particular attention to the collection and recording of materials. She considered that it was indispensable to master field folkloristics: it was compulsory to participate in fieldwork, to collect empirical material ourselves. She came with us in field practice, and demonstrated, from her own experience, how to work with our partners, how to obtain the result we yearned for, how to ask the proper questions (photo 2).

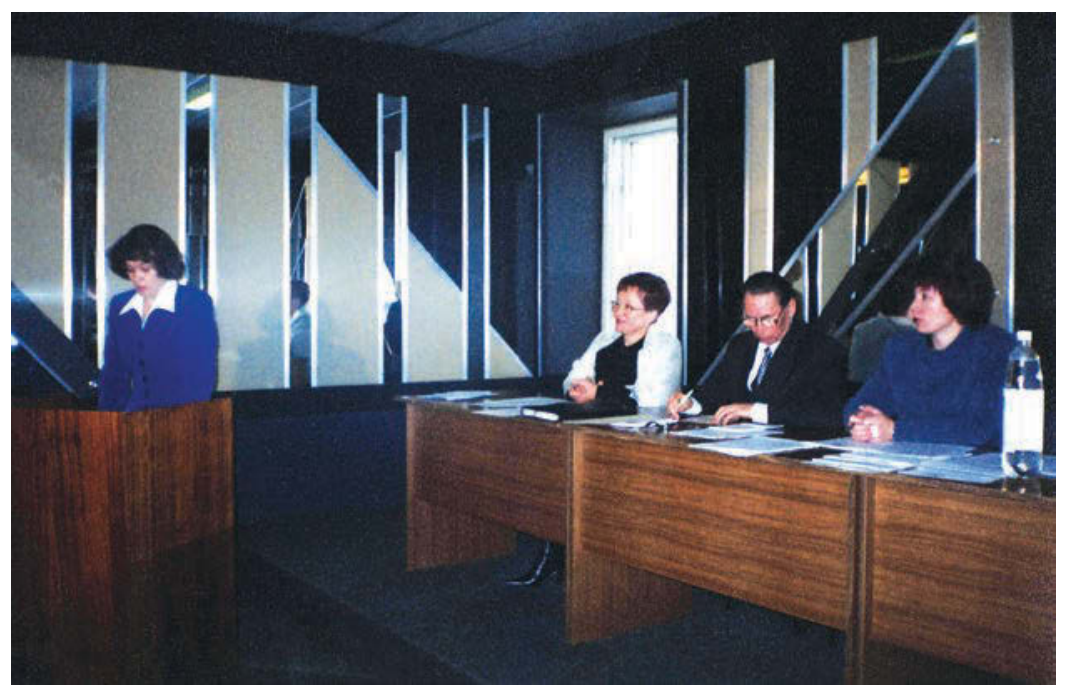

Photo 1. The defence of my PhD dissertation "The symbolic of mummering in the Udmurt's traditional culture". Izhevsk, UdIIYaL UrO RAN, December 2002. Photo G. Glukhova. 


\section{Galina Glukhova}
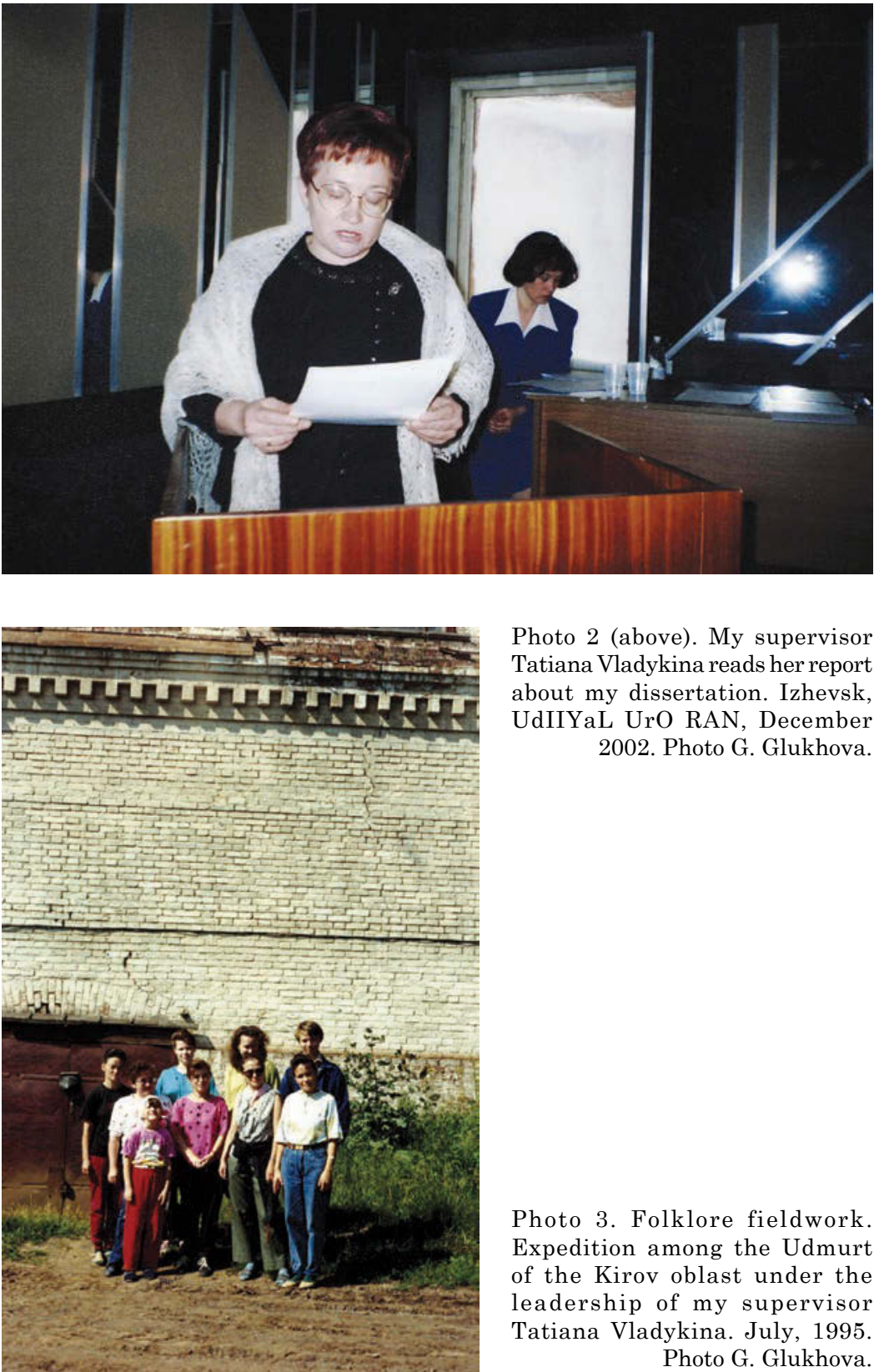

Photo 2 (above). My supervisor Tatiana Vladykina reads her report about my dissertation. Izhevsk, UdIIYaL UrO RAN, December 2002. Photo G. Glukhova.

Photo 3. Folklore fieldwork. Expedition among the Udmurt of the Kirov oblast under the leadership of my supervisor Tatiana Vladykina. July, 1995. Photo G. Glukhova. 




Photo 4. During our fellowship at the Estonian Literary Museum, Tartu (Estonia). April 1995. Photo G. Glukhova.

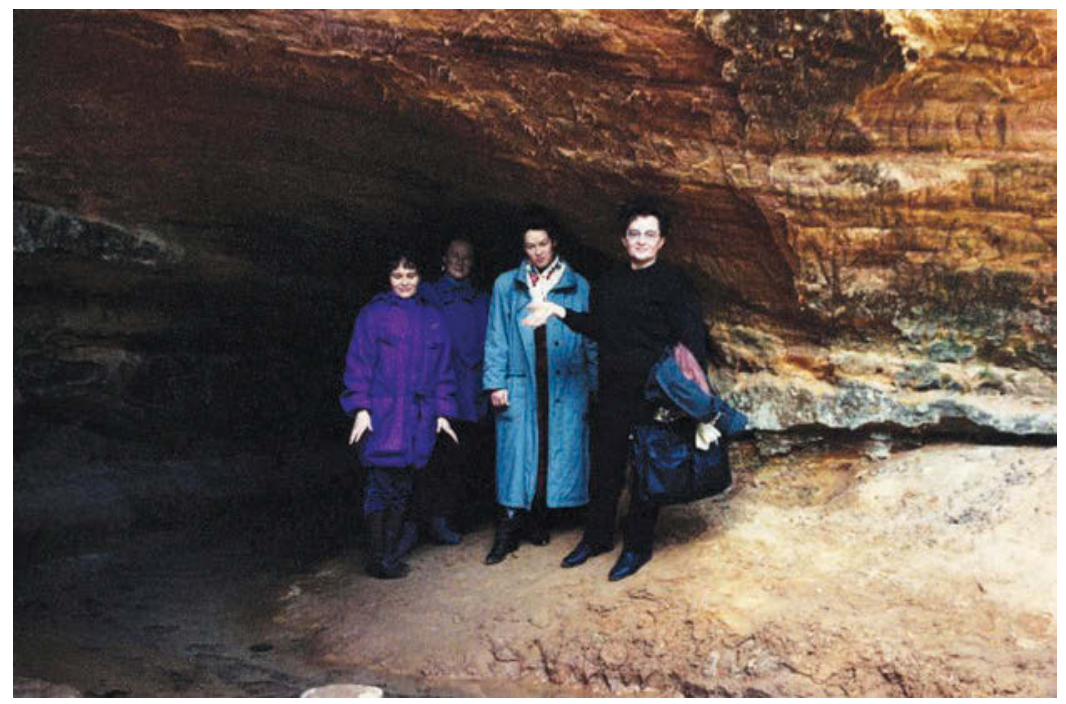

Photo 5. During our fellowship at the Estonian Literary Museum, Tartu (Estonia). April 1995. Photo G. Glukhova. 


\section{Galina Glukhova}

My first visit to Tartu (Estonia) was thanks to my supervisor. It was in 1995. Then for the first time, we discovered the scientific activity of the Estonian Literary Museum and had a glimpse into the world of research. We were stunned by the Museum's folklore archive. I think that the genuine enthusiasm, the indelible impression of what we saw there, also played an important role in what was to become my scientific path (photo 3).

Tatiana Vladykina is a highly moral personality, and she instructed her doctoral students in this spirit. She combined the talent of a great scholar and the experience of a gifted teacher and educator.

Now, we have already been acquainted with Tatiana Vladykina for more than a quarter of a century. Today she is for me more than merely a colleague, a mentor and a friend. She remains for me the Teacher, the one I want to resemble, to be as smart, as sympathetic, demanding, wise and decent.

Often I say to myself: "all I have as a teacher, and as a researcher, I have received from my University teachers, and most of all from my Teacher and Mentor Tatiana Vladykina”.



Galina Glukhova ( $\mathrm{PhD}$ ) is an associate professor and director of the Institute of Udmurt Philology, Finno-Ugric Studies and Journalism of Udmurt State University and teaches Udmurt literature and folklore. Her main field of interest is related to research on Udmurt and FinnoUgric folklore, Udmurt traditional culture, and the interaction of Udmurt folklore and literature. e-mail: galant@udm.ru 